\title{
Recent prospective data regarding good survival outcome after radiofrequency ablation of lung metastases from colorectal cancer: the radiation oncologist point of view
}

\author{
Linda Agollii, ${ }^{1,2}$ Luca Nicosia ${ }^{3}$ \\ ${ }^{1}$ Department of Radiation Oncology, ${ }^{2}$ OncoRay - National Center for Radiation Research in Oncology, Faculty of Medicine and University Hospital \\ Carl Gustav Carus, Technische Universität Dresden, Fetscherstraße 74, 01307 Dresden, Germany; ${ }^{3}$ Advanced Radiation Oncology Department, \\ IRCCS Sacro Cuore Don Calabria Hospital, Cancer Care Center, Verona, Italy
}

Correspondence to: Linda Agolli, MD. Department of Radiation Oncology, Faculty of Medicine and University Hospital Carl Gustav Carus, Technische Universität Dresden, Germany; OncoRay - National Center for Radiation Research in Oncology, Faculty of Medicine and University Hospital Carl Gustav Carus, Technische Universität Dresden, Fetscherstraße 74, 01307 Dresden, Germany. Email: linda.agolli@uniklinikum-dresden.de.

Provenance and Peer Review: This article was commissioned by the editorial office, Quantitative Imaging in Medicine and Surgery. The article did not undergo external peer review.

Comment on: Hasegawa T, Takaki H, Kodama H, Yamanaka T, Nakatsuka A, Sato Y, Takao M, Katayama Y, Fukai I, Kato T, Tokui T, Tempaku H, Adachi K, Matsushima Y, Inaba Y, Yamakado K. Three-year survival rate after radiofrequency ablation for surgically resectable colorectal lung metastases: A prospective multicenter study. Radiology 2020;294:686-95.

Submitted Mar 31, 2020. Accepted for publication Apr 20, 2020.

doi: 10.21037/qims-2020-13

View this article at: http://dx.doi.org/10.21037/qims-2020-13

About $20 \%$ of patients with colorectal cancer (CRC) present metastatic spread at diagnosis and another $20-30 \%$ of them will develop distant progression after curative resection of the primary tumor (1). In the last years, the available treatment for lung metastases has been progressively improved due to implementation of modern non-invasive or minimally invasive techniques. Their use could be able to improve survival in the oligometastatic state of selected categories of patient with slow growth tumor disease (2). Surgery is the most used treatment in the oligometastatic disease of patients with primary CRC, followed by stereotactic body radiotherapy (SBRT) called also stereotactic ablative radiotherapy (SABR). SABR is a non-invasive procedure that could be used in patients not suitable to surgery, due to comorbidities or advanced age, obtaining high rates of local control comparable to surgical series (3-5). A meta-analysis by Cao et al. (6) regarding SBRT of lung metastases analyzing 18 relevant studies in this field, reported 3-year local control (LC), overall survival (OS) and progression-free survival (PFS) of $60 \%, 52 \%$ and
$13 \%$, respectively. More recently, radiofrequency ablation (RFA) is acquiring an increased interest in the scientific community due to its effectiveness and safety. This kind of therapy is minimally invasive, could be performed with less costs in one treatment procedure and could be repeated in case of residual or recurrent local disease. However, evidence regarding RFA is still weak due to leak of large retrospective data and poor clinical use compared to surgery or SABR. Data analysis in a large series patients included in the CLOCC trial (7), reported $14,5 \%$ of local recurrence per patient an $6 \%$ per lesion after RFA of liver metastases from CRC. Moreover, for lesion $<3 \mathrm{~cm}$, tumor recurrence rates were demonstrated to be under $3 \%$. RFA could also be repeated up to four times in the treatment of small lung metastases $<2-3 \mathrm{~cm}(8)$.

In this scenario, prospective studies could provide further evidence regarding benefits of RFA in the treatment of pulmonary oligometastatic CRC patients. In the recently published prospective single-arm multicenter study by Hasegawa et al. (9), conducted in Japan, good results are 
reported in 70 patients with 100 lung metastases treated with RFA between 2008 and 2014. The primary end-point was 3-year OS calculated from initial RFA. In the statistical analysis, the expected 3 -year OS was $53 \%$, which is in line with surgical series. Other secondary end-points were prognostic factors, success and safety of treatment, disease control and survival, and changes in pulmonary function. Eligible patients were those with previously radically resected primary tumor and with no extrapulmonary metastases, a maximum of five parenchymal lung metastases measuring $\leq 3 \mathrm{~cm}$ (range: $0.4-2.8 \mathrm{~cm}$ ), and life expectancy $>1$ year. Although, inclusions criteria such as "both RFA and resection could be performed with technical success of" and "no severe comorbid disease" were stated, $11 \%$ of the patients were not suitable to surgery because of advanced age ( $\geq 80$ years) or comorbid conditions. The other $89 \%$ of the patients were potentially operable but they refused surgery. A positron emission tomographycomputed tomography (PET-CT) was performed before initial FRA and 1 year afterward in the follow up time for all patients. Chemotherapy was administered in $20 \%$ of the treated patients before RFA and another about $20 \%$ received adjuvant chemotherapy after lung RFA. Ablative radiofrequency of lung metastases was performed by 9 interventional radiologists. Technical success of the treatment war proved with CT imaging 1 month after the procedure and was defined as the full coverage of the tumor by the ablation zone. Repeated RFA was performed by unsuccessful therapy. Mean age was 66 years and most of the patients presented with single lung metastasis (70\%). In the remaining $30 \%$ of the patients with multiple lung metastases, lung RFA was conducted also in multiple sessions within 8 weeks. The final follow-up was concluded in 2018 and a central diagnostic committee consisted in 7 certified diagnostic radiologist checked technical success and disease progression. The 3 -year OS rate was $84 \%$ (59/70 analyzed patients) compared to the expected $53 \%$ previously calculated. In the multivariate analysis, rectal primary tumor location $(\mathrm{P}<0.001)$, positive carcinoembryonic antigen (CEA) $(\mathrm{P}=0.001)$ and no administration of chemotherapy before lung RFA $(\mathrm{P}<0.001)$ were significantly associated to worse OS. Primary and secondary treatment success rates were $96 \%$ and $100 \%$, respectively, with repeated RFA procedure in 3 patients. Overall, 88 sessions were performed for the 100 lung metastases; cooled electrodes were used in 84 sessions and multi-tined expandable electrodes in 4 sessions. In 6 patients (9\%) local tumor progression occurred at the time interval of 6-19 months after the initial
RFA. The 3-year PFS rate was $41 \%$ and half of the patients developed other new sites of pulmonary or extrapulmonary metastases, demonstrating that despite a good LC the use of combined systemic therapy is mandatory in this category of patients. In $20 \%$ of RFA sessions, patients developed pneumothorax, described as a grade 2 side effect that requires a temporary chest tube insertion. In addition, in another $16 \%$ of RFA session, treated patients developed grade 1 pneumothorax (12 patients), pleural effusion (1 patient), and pulmonary hemorrhage (1 patient), that were resolved without any treatment. A grade 5 adverse event was seen in one of the 88 RFA sessions. The principal limitation of the current study is lacking data regarding long-term toxicity and lung function.

To date, SBRT can count on very large series, also prospective, and with long-term results $(2,4,5,10)$, while experience with RFA is limited to small series. The commented study by Hasegawa et al. (9) represents one of the largest series prospectively evaluated with 3 -year reported outcome. The first major difference between SBRT and RFA is represented by lesion size. SBRT has technically no size limitation, even though the incidence of severe side effects increases significantly for lung metastases $>5 \mathrm{~cm}$ treated with ablative doses (biological effective dose- BED >100 Gy). For this reason, a hypofractionated radiation regimen rather than an ablative radiation dose is recommended in the treatment of lung tumors $\geq 5 \mathrm{~cm}$. Actual evidence regarding lung RFA is mainly limited to small lesions (20-30 $\mathrm{mm}$ diameter) (11). The proximity of the lung tumors to pulmonary vessel might reduce effectiveness and ablation diameter of RFA due to vascular cooling and, in turn, its use in the treatment of lung tumors (12-14). However, RFA could be a good treatment option in the treatment of liver metastases from CRC as reported in some retrospective studies $(7,13)$.

We should emphasize, that the excellent tumor control could be due to the very small diameter of treated lesions (median $10 \mathrm{~mm}$ ) in the study by Hasegawa et al. (9), with some lung metastases measuring $4 \mathrm{~mm}$, whose nature would be difficult to assess, even after performed PET-TC.

One interesting aspect of RFA is the rapid response evaluation. In particular, only one month after the RFA procedure a "technical success", defined, as the complete ablation of macroscopic tumor, could be assessed (15). In case of missing technical success, the lesion could be treated with further RFA. Response evaluation of lung SBRT is slightly different. SBRT might trigger an inflammatory process in the lung parenchyma, determining 
local lymphocyte infiltration and cytokines release. On diagnostic CT imaging, treated lung lesions could appear with increased diameter and a higher uptake on metabolic/ functional imaging might persist for months. Moreover, late response after SBRT could sometimes develop an intensive local lung fibrosis that can mimic a locoregional tumor progression, the so-called "mass-like" fibrosis (16). Therefore, clinical experience and dynamic imaging performance are required for an accurate tumor response evaluation.

The toxicity profile after RFA seems to be acceptable, but some observations are necessary. In the study of Hasegawa et al. (9), the most frequent toxicities are represented by hemorrhage and pneumothorax of grade $\leq 2$ in about $36 \%$ of RFA session. Although, a good $20 \%$ of the patients experiences grade 2 pneumothorax requiring an invasive chest tube placement. These patients probably necessitated a hospitalization, which increased costs of RFA due to complications. Only one (1.4\%) fatal hemorrhage occurred in a patients treated for a small lung metastasis. Long-term complications remains unknown. Compared to RFA, lung SBRT is characterized by $3-5 \%$ of severe pneumonitis (grade $\geq 3$ ) and toxic death are exceptional. The majority of lung SBRT-related toxicities could be managed with medication and usually only grade 4 toxicities might require invasive procedures, confirming once again safety and the non-invasive nature of SBRT.

Due to primary tumor radioresistance, lung metastases from CRC require higher biological effective dose (BED) compared to early NSCLC to obtain a good local control. Recently, Wang et al. demonstrated a better LC of lung metastases from CRC after ablative radiotherapy when a total doses of $60 \mathrm{~Gy} / 5$ fractions (BED10=132 Gy) was delivered (17). With modern techniques in radiation oncology, the achievement of high dose to the target without compromising surrounding healthy tissue is possible, as confirmed in many studies. A direct comparison of different therapy option such as surgery, SBRT and RFA is currently missing. Prospective studies with larger series are needed in this field.

In conclusion, SBRT could be considered an important option of radical local therapy for the management of lung metastases in the oligometastatic state of CRC. At the same time, good survival outcomes for small metastases from CRC were demonstrated after RFA. A multidisciplinary team should carefully select patients, who could benefit from a radical local therapy in the oligometastatic setting. Prospective data could better answer this issue.

\section{Acknowledgments}

Funding: None.

\section{Footnote}

Conflicts of Interest: Both authors have completed the ICMJE uniform disclosure form (available at http://dx.doi. org/10.21037/qims-2020-13). The authors have no conflicts of interest to declare.

Open Access Statement: This is an Open Access article distributed in accordance with the Creative Commons Attribution-NonCommercial-NoDerivs 4.0 International License (CC BY-NC-ND 4.0), which permits the noncommercial replication and distribution of the article with the strict proviso that no changes or edits are made and the original work is properly cited (including links to both the formal publication through the relevant DOI and the license). See: https://creativecommons.org/licenses/by-nc-nd/4.0/.

\section{References}

1. Eadens MJ, Grothey A. Curable metastatic colorectal cancer. Curr Oncol Rep 2011;13:168-76.

2. Palma DA, Olson R, Harrow S, Gaede S, Louie AV, Haasbeek C, Mulroy L, Lock M, Rodrigues GB, Yaremko BP, Schellenberg D, Ahmad B, Griffioen G, Senthi S, Swaminath A, Kopek N, Liu M, Moore K, Currie S, Bauman GS, Warner A, Senan S. Stereotactic ablative radiotherapy versus standard of care palliative treatment in patients with oligometastatic cancers (SABRCOMET): a randomised, phase 2, open-label trial. Lancet 2019;393:2051-8.

3. Agolli L, Bracci S, Nicosia L, Valeriani M, De Sanctis V, Osti MF. Lung Metastases Treated With Stereotactic Ablative Radiation Therapy in Oligometastatic Colorectal Cancer Patients: Outcomes and Prognostic Factors After Long-Term Follow-Up. Clin Colorectal Cancer 2017;16:58-64.

4. Osti MF, Agolli L, Valeriani M, Reverberi C, Bracci S, Marinelli L, De Sanctis V, Cortesi E, Martelli M, De Dominicis C, Minniti G, Nicosia L. 30 Gy single dose stereotactic body radiation therapy (SBRT): Report on outcome in a large series of patients with lung oligometastatic disease. Lung Cancer 2018;122:165-70.

5. Klement RJ, Abbasi-Senger N, Adebahr S, Alheid H, Allgaeuer M, Becker G, Blanck O, Boda-Heggemann 
J, Brunner T, Duma M, Eble MJ, Ernst I, Gerum S, Habermehl D, Hass P, Henkenberens C, Hildebrandt G, Imhoff D, Kahl H, Klass ND, Krempien R, Lewitzki V, Lohaus F, Ostheimer C, Papachristofilou A, Petersen C, Rieber J, Schneider T, Schrade E, Semrau R, Wachter S, Wittig A, Guckenberger M, Andratschke N. The impact of local control on overall survival after stereotactic body radiotherapy for liver and lung metastases from colorectal cancer: a combined analysis of 388 patients with 500 metastases. BMC Cancer 2019;19:173.

6. Cao C, Wang D, Tian DH, Wilson-Smith A, Huang $\mathrm{J}$, Rimner A. A systematic review and meta-analysis of stereotactic body radiation therapy for colorectal pulmonary metastases. J Thorac Dis 2019;11:5187-98.

7. Tanis E, Nordlinger B, Mauer M, Sorbye H, van Coevorden F, Gruenberger T, Schlag PM, Punt CJ, Ledermann J, Ruers TJ. Local recurrence rates after radiofrequency ablation or resection of colorectal liver metastases. Analysis of the European Organisation for Research and Treatment of Cancer \#40004 and \#40983. Eur J Cancer 2014;50:912-9.

8. de Baère T, Aupérin A, Deschamps F, Chevallier P, Gaubert Y, Boige V, Fonck M, Escudier B, Palussiére J. Radiofrequency ablation is a valid treatment option for lung metastases: experience in 566 patients with 1037 metastases. Ann Oncol 2015;26:987-91.

9. Hasegawa T, Takaki H, Kodama H, Yamanaka T, Nakatsuka A, Sato Y, Takao M, Katayama Y, Fukai I, Kato T, Tokui T, Tempaku H, Adachi K, Matsushima Y, Inaba Y, Yamakado K. Three-year survival rate after radiofrequency ablation for surgically resectable colorectal lung metastases: A prospective multicenter study. Radiology 2020;294:686-95.

10. Rieber J, Streblow J, Uhlmann L, Flentje M, Duma M, Ernst I, Blanck O, Wittig A, Boda-Heggemann J, Krempien R, Lohaus F, Klass ND, Eble MJ, Imhoff D, Kahl H, Petersen C, Gerum S, Henkenberens C, Adebahr S, Hass P, Schrade E, Wendt TG, Hildebrandt G, Andratschke N, Sterzing F, Guckenberger M. Stereotactic body radiotherapy (SBRT) for medically inoperable lung metastases-A pooled analysis of the German working group "stereotactic radiotherapy". Lung Cancer 2016;97:51-8.

11. Schlijper RC, Grutters JP, Houben R, Dingemans AM, Wildberger JE, Van Raemdonck D, Van Cutsem E, Haustermans K, Lammering G, Lambin P, De Ruysscher D. What to choose as radical local treatment for lung metastases from colo-rectal cancer: surgery or radiofrequency ablation? Cancer Treat Rev 2014;40:60-7.

12. Poch FGM, Neizert CA, Gemeinhardt O, Geyer B, Eminger K, Rieder C, Niehues SM, Vahldiek J, Thieme SF, Lehmann KS. Intermittent Pringle maneuver may bebeneficial for radiofrequency ablations in situations with tumor-vessel proximity. Innov Surg Sci 2018;3:245-51.

13. Park MH, Cho JS, Shin BS, Jeon GS, Lee B, Lee K. Comparison of internally cooled wet electrode and hepatic vascular inflow occlusion method for hepatic radiofrequency ablation. Gut Liver 2012;6:471-5.

14. Li M, Zhang W, Li Y, Li P, Li J, Gong J, Chen Y. Radiofrequency-assisted versus clamp-crushing parenchyma transection in cirrhotic patients with hepatocellular carcinoma: a randomized clinical trial. Dig Dis Sci 2013;58:835-40.

15. Ahmed M, Solbiati L, Brace CL, Breen DJ, Callstrom MR, Charboneau JW, Chen MH, Choi BI, de Baère T, Dodd GD 3rd, Dupuy DE, Gervais DA, Gianfelice D, Gillams AR, Lee FT Jr, Leen E, Lencioni R, Littrup PJ, Livraghi T, Lu DS, McGahan JP, Meloni MF, Nikolic B, Pereira PL, Liang P, Rhim H, Rose SC, Salem R, Sofocleous CT, Solomon SB, Soulen MC, Tanaka M, Vogl TJ, Wood BJ, Goldberg SN. Image-guided tumor ablation: standardization of terminology and reporting criteria-a 10-year update. Radiology 2014;273:241-60.

16. Dunlap NE, Yang W, McIntosh A, Sheng K, Benedict SH, Read PW, Larner JM. Computed tomography-based anatomic assessment overestimates local tumor recurrence in patients with mass-like consolidation after stereotactic body radiotherapy for early-stage non-small cell lung cancer. Int J Radiat Oncol Biol Phys 2012;84:1071-7.

17. Wang X, Zamdborg L, Ye H, Grills IS, Yan D. A matchedpair analysis of stereotactic body radiotherapy (SBRT) for oligometastatic lung tumors from colorectal cancer versus early stage non-small cell lung cancer. BMC Cancer 2018;18:962.

Cite this article as: Agolli L, Nicosia L. Recent prospective data regarding good survival outcome after radiofrequency ablation of lung metastases from colorectal cancer: the radiation oncologist point of view. Quant Imaging Med Surg 2020;10(5):1182-1185. doi: 10.21037/qims-2020-13 